\title{
Application of a Plackett-Burman Design for Screening Raw Materials Mainly Affecting the Properties of Mum (Thai Fermented Sausage)
}

\author{
Attapol Sutjaritrak ${ }^{1}$, Pairote Wiriyacharee ${ }^{1,2,3}$, \\ Pattavara Pathomrungsiyounggul ${ }^{1 *}$, Charin Techapun ${ }^{1}$, \\ and Puangtong Jaisun ${ }^{1}$
}

${ }^{1}$ School of Agro-Industry, Faculty of Agro-Industry, Chiang Mai University, Chiang Mai 50100, Thailand

${ }^{2}$ Science and Technology Research Institute of Chiang Mai University, Chiang Mai 50200, Thailand

${ }^{3}$ Center of Excellence in Microbial Diversity and Sustainable Utilization, Faculty of Science, Chiang Mai University, Chiang Mai 50200, Thailand

*Corresponding author: E-mail: pattavara.p@cmu.ac.th

https://doi.org/10.12982/CMUJNS.2020.0008

Received: March 12, 2019

Revised: June 4, 2019

Accepted: June 7, 2019

\begin{abstract}
The objective of this study was to screen the factors that play an important role on quality of Thai fermented sausage (Mum) by using the Plackett-Burman screening design. The studied factors included 5 ingredients for Mum production namely minced garlic, roasted rice powder, salt, ground glutinous rice and sodium nitrite and 4 starter culture species, Pediococcus acidilactici KK3, Weissella cibaria CM7, Lactobacillus plantarum subsp. plantarum CP1, and L. plantarum subsp. plantarum KK6. According to the experimental design, twelve treatments of Mum were produced and then analyzed for sensorial quality (color, odor, homogeneity, hardness, sourness, saltiness and overall acceptability), $\mathrm{pH}$, total acidity and texture (shear force). The analysis showed that among various studied factors, salt, sodium nitrite and $P$. acidilactici KK3 were the main factors influencing Mum quality.
\end{abstract}

Keywords: Fermented sausage, Ingredient, Mum, Plackett-Burman design, Quality of sausage, Starter culture

\section{INTRODUCTION}

Mum is a traditional fermented sausage mainly produced in northeastern region of Thailand. Its major compositions include minced meat and minced 
liver of cow, pig or buffalo. Other ingredients are salt, saltpeter, garlic, roasted rice powder and sticky rice. The recipe and the processing conditions vary among the producers. Generally, ground meat and liver are mixed well prior to addition of other ingredients and then the mixture is stuffed in natural intestine or appendix. The sausage is then left to ferment at ambient temperature $\left(25-30^{\circ} \mathrm{C}\right)$ for 2-3 days. During fermentation, lactic acid is produced by microorganisms found naturally in an environment. The final characteristics of the most acceptable Mum recipe have been reported with $\mathrm{pH}$, lactic acid content, salt content and moisture content of 4.57, 1.23\%, 1.63\% and $52.72 \%$, respectively (Cheijarern, 1988). Several fermented sausages such as Sucuk (Soyer et al., 2005), Nham (Jaichumjai et al., 2010), Salami (Coffey et al., 1998) and Chorizo (González-Fernández et al., 2003) produced by application of starter cultures have been studied. Nowadays, food industry increases their interest to manufacture sausages fermented by utilizing starter cultures due to rapid fermentation, producing safe products with consistent quality. To date, no researchers have studied the effects of utilizing starter culture in production of Mum, although a researcher (Maipueang, 1988) has isolated the lactic acid bacteria species and reported that Pediococcus cerevisiae, Lactobacillus plantarum, L. brevis, Leuconostoc mesenteroides, and $P$. homari were the main lactic acid bacteria grown during Mum fermentation. In addition, the optimum content of salt and glutinous rice (Cheijarern, 1988) and sodium nitrite and sodium ascorbate (Yordrak, 2003) for Mum production without starter culture inoculation has been studied. Therefore, optimum content of ingredients in Mum fermented by starter culture should be investigated. The product optimization has been carried out using a two-steps experimental design. The first step involves screening to investigate the critical control factors from many potential factors and the later step involves optimizing the level of those factors so that the product having the desirable quality is obtained (Joglekar and May, 1991). Plackett-Burman design is a well-known, quick and reliable statistical technique that enables the food researchers to solve the screening problem (Hu, 1999). It is partial factorial design, where large numbers of independent variables $(\mathrm{N})$ are studied in small number of experiments $(\mathrm{N}+1)$. Although application of this design is impossible to measure the effects of interactions, this is not usually important in screening as the main objective is to isolate the important variables (Anderson, 1981). With Plackett-Burman design, Li et al. (2007) could identify that 5 culture components out of 17 had the significant effects on xylanase production. Modi and Maya (2008) were able to screen 11 potential ingredients to formulate the extended meat cubes while Phromraksa et al. (2003) concluded that only 3 major factors from 9 were the main factors affecting chemical, physical and sensory properties of Sai Krok Prew, a Thai fermented sausage. The objective of this study was to screen the factors including ingredients and type of lactic acid bacteria that mainly influenced 
the quality of Mum, by using a Plackett-Burman design, for further study in optimizing formulation of Mum.

\section{MATERIALS AND METHODS}

\section{Raw materials preparation}

Fresh pork hams were trimmed to remove all visible fat whereas pig livers were cooked in boiling water. Trimmed pork and cooked livers were minced separately in a food processor. The ratio of minced pork to minced liver was 5:1.

Steamed glutinous rice was rinsed through drinking water to remove the sticky layer. Garlic was peeled and dry glutinous rice was roasted at $175 \pm 5^{\circ} \mathrm{C}$ for $1 \mathrm{~min}$ in a pan. The above ingredients were ground separately in a blender. Salt (sodium chloride) and sodium nitrite were weighed and mixed together.

\section{Starter cultures preparation}

Starter cultures employed in this study were $P$. acidilactici KK3, Weissella cibaria CM7, L. plantarum subsp. plantarum CP1, and L. plantarum subsp. plantarum KK6. They were obtained from Traditional Food Research and Development Unit, Science and Technology Research Institute, Chiang Mai University. The obtained starter culture was activated in Lactobacillus de Man, Rogosa and Sharpe (MRS) broth (Difco Laboratories, USA.) at $30^{\circ} \mathrm{C}$ for $24 \mathrm{~h}$. A loopful of cultured broth was streaked onto Lactobacillus MRS agar (Difco Laboratories, USA.) and incubated at $30^{\circ} \mathrm{C}$ for $24 \mathrm{~h}$. Then a single colony was taken by a loop to streak on the MRS slant and stored at $4^{\circ} \mathrm{C}$ until use. A loop of culture from MRS slant was taken into $5 \mathrm{~mL}$ MRS broth and incubated at $30^{\circ} \mathrm{C}$ for $24 \mathrm{~h}$, to obtain starter culture $9 \mathrm{Log} \mathrm{cfu} / \mathrm{mL}$.

\section{Mum preparation}

Minced pork was mixed with minced liver for 1 min using a mixer (Model 5K5SS, Kitchen Aid, USA). The mixture of salt and sodium nitrite was added and mixed for $1 \mathrm{~min}$. Ground glutinous rice and ground garlic were added and mixed for $1 \mathrm{~min}$. Roasted rice powder was added and mixed for $1 \mathrm{~min}$. Finally, starter cultures were added into the meat mixture and mixed for $1 \mathrm{~min}$. The mixture was then stuffed into $2.3-\mathrm{cm}$ diameter collagen casings (Nippi casing, Nippi Incorporated, Japan) and tied with thread at $15 \mathrm{~cm}$ intervals. Mums were fermented in an incubator at $30^{\circ} \mathrm{C}$ for $72 \mathrm{~h}$.

\section{pH analysis}

Mum $(10 \mathrm{~g})$ was blended with $100 \mathrm{~g}$ distilled water and $\mathrm{pH}$ was measured using a digital $\mathrm{pH}$ meter (Orion: Model 520A, USA), according to AOAC (2000). The analysis was conducted in triplicate. 


\section{Total acidity analysis}

Total acidity was determined as percentage of lactic acid by titrating with $0.1 \mathrm{~N} \mathrm{NaOH}$, using phenolphthalein as an indicator AOAC (2000). The analysis was carried out in 3 replications.

\section{Shear force analysis}

Mum sausages were cut into slices of $1 \mathrm{~cm}$ thickness and then cooked in a microwave (LG Electronic : Model MS-2342C, China) at 800 watt for $1 \mathrm{~min}$. Texture of cooked Mums was measured using an Instron universal testing machine (Model 5565, USA), controlled by computer with Warner Bratzler blade, equipped with a load cell of $5 \mathrm{~kg}$ at a crosshead speed of $200 \mathrm{~mm} / \mathrm{min}$. Maximum force to cut sample (shear force) was the measured parameter. The analysis was performed in 3 replications.

\section{Organoleptic analysis}

Mum was sliced to $1.0 \mathrm{~cm}$ thickness. The slices of Mum were cooked in a microwave (LG Electronic : Model MS-2342C, China) at 800 watt for $1 \mathrm{~min}$. The ideal ratio profile technique was used for development of the final product in terms of optimal organoleptic quality. Sensory panel of 15 members were asked to score the sensory characteristics of samples i.e. color, homogeneity, sourness, saltiness, odor, hardness and overall acceptability in comparison to their ideal product characteristics. These attributes were then used as dependent variables. An ideal ratio score of 1 indicates that the attribute is at the ideal level therefore no improvement needed for that attribute whereas a ratio score less than 1 indicates that the intensity of that attribute is lower than ideal level and a ratio score higher than 1 means that the intensity of attribute is higher than ideal level (Cooper et al., 1989).

\section{Experimental design}

The Plackett-Burman design was used for investigating the main variables affecting the quality of Mum. Owing to 9 input variables (minced garlic, roasted rice powder, salt, ground glutinous rice, sodium nitrite, $P$. acidilactici KK3, L. plantarum CP1, L. plantarum KK6 and Weissella cibaria CM7), the PlackettBurman matrix of 12 treatments (Hu, 1999) was used in this study and it provided 2 dummy variables from which the error was estimated (Table 1). Each variable represented at 2 levels, high and low, which were denoted by +1 and -1 , respectively. The quantity of each variable at high level and low level is presented in Table 2. To obtain each starter culture $6 \mathrm{Log} \mathrm{cfu} / \mathrm{g}$, the prepared starter culture in MRS broth was pipetted $1 \mathrm{~mL}$ per $1 \mathrm{~kg}$ of minced pork. Twelve treatments were fully randomized so that no 'order' bias would be introduced. 
Table 1. Plackett and Burman experimental design matrix.

\begin{tabular}{|c|c|c|c|c|c|c|c|c|c|c|c|}
\hline \multicolumn{12}{|c|}{ Input variables } \\
\hline 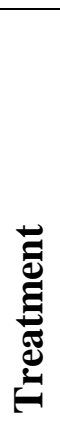 & 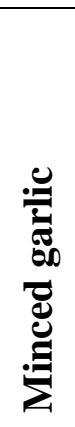 & 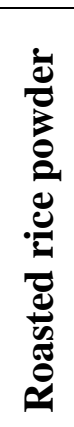 & 竞 & 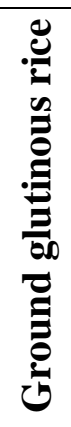 & 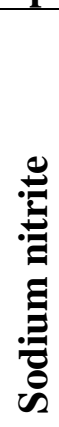 & 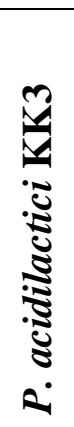 & 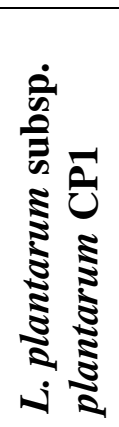 & 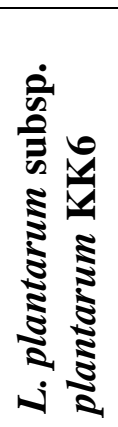 & 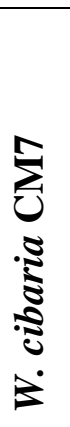 & 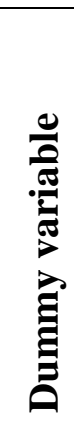 & 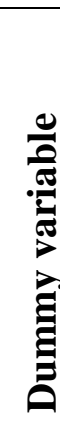 \\
\hline 1 & +1 & +1 & -1 & +1 & +1 & +1 & -1 & -1 & -1 & +1 & -1 \\
\hline 2 & +1 & -1 & +1 & +1 & +1 & -1 & -1 & -1 & +1 & -1 & +1 \\
\hline 3 & -1 & +1 & +1 & +1 & -1 & -1 & -1 & +1 & -1 & +1 & +1 \\
\hline 4 & +1 & +1 & +1 & -1 & -1 & -1 & +1 & -1 & +1 & +1 & -1 \\
\hline 5 & +1 & +1 & -1 & -1 & -1 & +1 & -1 & +1 & +1 & -1 & +1 \\
\hline 6 & +1 & -1 & -1 & -1 & +1 & -1 & +1 & +1 & -1 & +1 & +1 \\
\hline 7 & -1 & -1 & -1 & +1 & -1 & +1 & +1 & -1 & +1 & +1 & +1 \\
\hline 8 & -1 & -1 & +1 & -1 & +1 & +1 & -1 & +1 & +1 & +1 & -1 \\
\hline 9 & -1 & +1 & -1 & +1 & +1 & -1 & +1 & +1 & +1 & -1 & -1 \\
\hline 10 & +1 & -1 & +1 & +1 & -1 & +1 & +1 & +1 & -1 & -1 & -1 \\
\hline 11 & -1 & +1 & +1 & -1 & +1 & + & + & -1 & -1 & -1 & +1 \\
\hline 12 & -1 & -1 & -1 & -1 & -1 & -1 & -1 & -1 & -1 & -1 & -1 \\
\hline
\end{tabular}

Table 2. Quantity of 9 input variables at low and high level.

\begin{tabular}{lll}
\hline \multirow{2}{*}{\multicolumn{1}{c}{ Variables }} & \multicolumn{2}{c}{ Quantity (based on minced pork) } \\
\cline { 2 - 3 } & Low level (-1) & High level (+1) \\
\hline Ground garlic & $10 \%$ & $20 \%$ \\
Roasted rice powder & $1 \%$ & $5 \%$ \\
Salt & $2 \%$ & $4 \%$ \\
Ground glutinous rice & $5 \%$ & $10 \%$ \\
Sodium nitrite & $0.010 \%$ & $0.015 \%$ \\
P. acidilactici KK3 & $0 \mathrm{Log} \mathrm{cfu} / \mathrm{g}$ & $6 \mathrm{Log} \mathrm{cfu} / \mathrm{g}$ \\
L. plantarum subsp. plantarum CP1 & $0 \mathrm{Log} \mathrm{cfu} / \mathrm{g}$ & $6 \mathrm{Log} \mathrm{cfu} / \mathrm{g}$ \\
L. plantarum subsp. plantarum KK6 & $0 \mathrm{Log} \mathrm{cfu} / \mathrm{g}$ & $6 \mathrm{Log} \mathrm{cfu} / \mathrm{g}$ \\
W. cibaria CM7 & $0 \mathrm{Log} \mathrm{cfu} / \mathrm{g}$ & $6 \mathrm{Log} \mathrm{cfu} / \mathrm{g}$ \\
\hline
\end{tabular}




\section{Data analysis}

The effect of each input variable on each dependent variable was determined according to Wiriyacharee (2012) using the following equation;

$$
\text { Effect of input variable }=\frac{\Sigma \mathrm{H}}{6}-\frac{\sum \mathrm{L}}{6}
$$

where, $\mathrm{H}$ and $\mathrm{L}$ were the value of the dependent variable at high level and low level of the same input variable. When the sign was positive, the input variable directly related to value of the dependent variable and when the negative, the influence of input variable was inversely to value of the dependent variable. The above equation was also used to determine the effect of each dummy variable.

The effects of dummy variables were applied to test the real effect which resulted significantly from the input variables. This was performed by calculating standard error from the following equation (Wiriyacharee, 2012);

$$
\text { Standard error of effect }=\sqrt{\sum d^{2} / n}
$$

where, $d$ is the dummy effect and $\mathrm{n}$ is the number of dummy effects.

Statistical significance of effect of each input variable was identified by using t value.

$\mathrm{t}$ value $=$ Effect of input variable / Standard error of effect

Then, $t$ value obtaining from this calculation was compared with $t$ table at degree of freedom of 2 due to 2 dummy variables.

\section{RESULTS}

Table 3 presents $\mathrm{pH}$, total acidity and shear force of Mum produced by different levels of each factors, 12 treatments. It was found that $\mathrm{pH}$ and total acidity varied from 5.21 to 5.83 and from $0.26 \%$ to $0.33 \%$, respectively. Shear force of Mum 12 treatments was between $51.58 \mathrm{~N}$ and $57.03 \mathrm{~N}$. The ideal ratio score on homogeneity, sourness, odor and overall acceptability of all Mums were less than 1 but that on hardness was higher than 1 (Table 4 and 5).

The resulting effects of input variables on dependent variables and significant levels were presented in Table 6 and 7. A $P$-value more than 0.20 indicated the insignificance of effect. All input variables did not affect significantly $(P>0.2)$ on the ideal ratio score of hardness and overall acceptability of Mum (data not shown). The W. cibaria CM7 had no significant $(P>0.2)$ effect on all qualities. The other eight input variables influenced significantly at least one quality. Total acidity was influenced significantly $(P \leq 0.15)$ by four input variables whereas $\mathrm{pH}$ and shear force was affected significantly $(P \leq 0.20$ and $P \leq 0.15$, respectively) by only one input variable (Table 6 ). Among the sensory attributes, ideal ratio score of color was affected significantly by the most number 
of input variables (6 variables) whereas that of saltiness was influenced significantly by 1 variable.

Table 3. $\mathrm{pH}$, total acidity and shear force of Mum samples produced according to Plackett-Burman design.

\begin{tabular}{cccc}
\hline Treatment & $\mathbf{p H}$ & Total acidity $(\%)$ & Shear force $(\mathbf{N})$ \\
\hline 1 & $5.35 \pm 0.01$ & $0.29 \pm 0.01$ & $53.67 \pm 3.97$ \\
2 & $5.73 \pm 0.02$ & $0.27 \pm 0.01$ & $51.58 \pm 6.37$ \\
3 & $5.65 \pm 0.01$ & $0.27 \pm 0.01$ & $52.51 \pm 9.41$ \\
4 & $5.52 \pm 0.01$ & $0.29 \pm 0.02$ & $56.88 \pm 19.38$ \\
5 & $5.29 \pm 0.01$ & $0.30 \pm 0.01$ & $53.19 \pm 4.51$ \\
6 & $5.21 \pm 0.01$ & $0.29 \pm 0.02$ & $54.63 \pm 10.19$ \\
7 & $5.22 \pm 0.01$ & $0.33 \pm 0.01$ & $56.05 \pm 5.85$ \\
8 & $5.63 \pm 0.01$ & $0.28 \pm 0.01$ & $54.11 \pm 10.10$ \\
9 & $5.56 \pm 0.00$ & $0.29 \pm 0.02$ & $56.59 \pm 10.04$ \\
10 & $5.53 \pm 0.01$ & $0.31 \pm 0.01$ & $57.03 \pm 2.69$ \\
11 & $5.83 \pm 0.01$ & $0.26 \pm 0.01$ & $54.88 \pm 7.38$ \\
12 & $5.72 \pm 0.01$ & $0.27 \pm 0.01$ & $53.70 \pm 6.08$ \\
\hline
\end{tabular}

Note: Values are mean \pm SD of 3 replications.

Table 4. Ideal ratio score of color, homogeneity, sourness and saltiness of Mum produced according to Plackett-Burman design.

\begin{tabular}{ccccc}
\hline Treatment & Color & Homogeneity & Sourness & Saltiness \\
\hline 1 & $0.92 \pm 0.17$ & $0.73 \pm 0.23$ & $0.70 \pm 0.28$ & $0.96 \pm 0.31$ \\
2 & $0.96 \pm 0.15$ & $0.87 \pm 0.11$ & $0.79 \pm 0.32$ & $1.25 \pm 0.23$ \\
3 & $1.01 \pm 0.19$ & $0.75 \pm 0.18$ & $0.79 \pm 0.33$ & $1.30 \pm 0.19$ \\
4 & $1.04 \pm 0.20$ & $0.70 \pm 0.18$ & $0.79 \pm 0.31$ & $1.15 \pm 0.37$ \\
5 & $0.86 \pm 0.23$ & $0.67 \pm 0.21$ & $0.78 \pm 0.32$ & $0.90 \pm 0.29$ \\
6 & $0.89 \pm 0.18$ & $0.78 \pm 0.16$ & $0.72 \pm 0.30$ & $0.76 \pm 0.29$ \\
7 & $0.89 \pm 0.21$ & $0.76 \pm 0.17$ & $0.74 \pm 0.25$ & $0.88 \pm 0.24$ \\
8 & $0.89 \pm 0.26$ & $0.78 \pm 0.20$ & $0.77 \pm 0.33$ & $0.96 \pm 0.20$ \\
9 & $1.00 \pm 0.17$ & $0.76 \pm 0.16$ & $0.77 \pm 0.28$ & $0.99 \pm 0.38$ \\
10 & $0.82 \pm 0.31$ & $0.68 \pm 0.17$ & $0.84 \pm 0.33$ & $1.21 \pm 0.15$ \\
11 & $1.04 \pm 0.23$ & $0.73 \pm 0.18$ & $0.75 \pm 0.28$ & $1.27 \pm 0.24$ \\
12 & $0.88 \pm 0.18$ & $0.75 \pm 0.21$ & $0.71 \pm 0.28$ & $0.91 \pm 0.32$ \\
\hline
\end{tabular}


Table 5. Ideal ratio scores of odor, hardness and overall acceptability of Mum12 treatments produced according to Plackett-Burman design.

\begin{tabular}{cccc}
\hline Treatment & Odor & Hardness & Overall acceptability \\
\hline 1 & $0.88 \pm 0.29$ & $1.26 \pm 0.18$ & $0.49 \pm 0.18$ \\
2 & $0.92 \pm 0.20$ & $1.21 \pm 0.08$ & $0.49 \pm 0.14$ \\
3 & $0.97 \pm 0.19$ & $1.27 \pm 0.15$ & $0.43 \pm 0.17$ \\
4 & $0.91 \pm 0.22$ & $1.31 \pm 0.21$ & $0.41 \pm 0.15$ \\
5 & $0.89 \pm 0.19$ & $1.22 \pm 0.08$ & $0.45 \pm 0.17$ \\
6 & $0.90 \pm 0.14$ & $1.26 \pm 0.13$ & $0.49 \pm 0.20$ \\
7 & $0.89 \pm 0.21$ & $1.20 \pm 0.06$ & $0.56 \pm 0.13$ \\
8 & $0.81 \pm 0.15$ & $1.24 \pm 0.10$ & $0.48 \pm 0.17$ \\
9 & $0.91 \pm 0.12$ & $1.26 \pm 0.09$ & $0.44 \pm 0.15$ \\
10 & $0.95 \pm 0.17$ & $1.22 \pm 0.08$ & $0.42 \pm 0.20$ \\
11 & $0.85 \pm 0.16$ & $1.22 \pm 0.07$ & $0.50 \pm 0.17$ \\
12 & $0.84 \pm 0.19$ & $1.19 \pm 0.05$ & $0.48 \pm 0.23$ \\
\hline
\end{tabular}

Note: Values are mean \pm SD of 3 replications.

Table 6. Effects and significance level of input variables of $\mathrm{pH}$, total acidity and shear force of Mum.

\begin{tabular}{lccc}
\hline \multicolumn{1}{c}{ Input variables } & $\mathbf{p H}$ & $\begin{array}{c}\text { Total acidity } \\
(\mathbf{\%})\end{array}$ & $\begin{array}{c}\text { Shear force } \\
(\mathbf{N})\end{array}$ \\
\hline Ground garlic & -0.164 & 0.009 & -0.143 \\
Roasted rice power & 0.026 & -0.009 & 0.103 \\
Salt & $\mathbf{0 . 2 5 6 \mathbf { a }}$ & $\mathbf{- 0 . 0 1 5 b}$ & -0.140 \\
Ground glutinous rice & -0.026 & 0.011 & 0.007 \\
Sodium nitrite & 0.064 & $\mathbf{- 0 . 0 1 5 b}$ & -0.650 \\
P. acidilactici KK3 & -0.090 & $\mathbf{0 . 0 1 5 b}$ & 0.507 \\
L. plantarum subsp. plantarum CP1 & -0.084 & $\mathbf{0 . 0 1 5 b}$ & $\mathbf{2 . 8 8 3 b}$ \\
L. plantarum subsp. plantarum KK6 & -0.084 & 0.005 & 0.217 \\
W. cibaria CM7 & -0.056 & 0.011 & 0.330 \\
Dummy & -0.180 & 0.009 & 0.147 \\
Dummy & -0.064 & -0.009 & -1.523 \\
\hline Note: Letters a and b indicate significance level by t-test at $80 \%(P \leq 0.20)$ and $85 \%(P \leq 0.15)$, respectively.
\end{tabular}


Table 7. Effects and significance level of input variables on ideal ratio score of sensory properties of Mum.

\begin{tabular}{lccccc}
\hline \multicolumn{1}{c}{ Input variables } & Color & Homogeneity & Sourness & Saltiness & Odor \\
\hline Ground garlic & $\mathbf{- 0 . 0 3 7 b}$ & -0.017 & 0.015 & -0.014 & $\mathbf{0 . 0 3 0 a}$ \\
Roasted rice power & $\mathbf{0 . 0 9 0 d}$ & $\mathbf{- 0 . 0 4 7 b}$ & 0.001 & 0.100 & 0.017 \\
Salt & $\mathbf{0 . 0 5 3 c}$ & 0.010 & $\mathbf{0 . 0 5 1 c}$ & $\mathbf{0 . 2 9 0 d}$ & 0.017 \\
Ground glutinous rice & 0.000 & 0.023 & 0.019 & 0.106 & $\mathbf{0 . 0 5 3 c}$ \\
Sodium nitrite & $\mathbf{0 . 0 3 3 a}$ & $\mathbf{0 . 0 5 7 c}$ & -0.025 & -0.026 & $\mathbf{- 0 . 0 3 0 a}$ \\
$\begin{array}{l}\text { P. acidilactici KK3 } \\
\text { L. plantarum subsp. }\end{array}$ & $\mathbf{- 0 . 0 6 0 c}$ & $\mathbf{- 0 . 0 4 3 a}$ & 0.001 & -0.030 & $\mathbf{- 0 . 0 3 0 a}$ \\
plantarum CP1 & 0.027 & -0.023 & 0.011 & -0.004 & 0.017 \\
$\begin{array}{l}\text { L. plantarum } \text { subsp. } \\
\text { plantarum } \text { KK6 }\end{array}$ & $\mathbf{- 0 . 0 4 3 b}$ & -0.020 & $\mathbf{0 . 0 3 1 a}$ & -0.050 & 0.023 \\
$\begin{array}{l}\text { W. cibaria } \text { CM7 } \\
\text { Dummy }\end{array}$ & 0.013 & 0.020 & 0.021 & -0.046 & -0.010 \\
Dummy & 0.013 & 0.007 & -0.021 & -0.086 & 0.000 \\
\hline
\end{tabular}

Note: Letters a, b, c and d indicate significance level by t-test at $80 \%(P \leq 0.20), 85 \%(P \leq 0.15), 90 \%$ $(P \leq 0.10)$ and $95 \%(P \leq 0.05)$, respectively.

\section{DISCUSSION}

The $\mathrm{pH}$ and total acidity values obtaining from experimental analysis in all Mum samples were higher and lower, respectively, than those reported by Vichitphan et al. (2008) who studied the chemical quality of commercial Mum (pH 5.02 and $1.66 \%$ total acidity) and by Metha and Sereepaowong (1998) who produced Mum from beef, liver, lung and heart ( $\mathrm{pH} 4.49$ and $2.95 \%$ total acidity). Shear force indicates the force to cut an object (Lu and Abbott, 2004). So far, shear force values of Mum have never been reported. However, shear force in the breakfast sausages and the pork sausages were 11.13 - 16.25 N (Yang et al., 2015) and $115-150 \mathrm{~N}$ (Barbut et al., 2016), respectively. It should be noted that shear force value required for Mum cutting was in between that of the breakfast sausages and the pork sausages.

To screen the important input variables (raw materials) for Mum production, the effects of each input variable affecting various properties of Mum were examined.

The minced garlic significantly affected ideal ratio score of two sensory attributes, color and odor (Table 7) but did not show a significant effect on chemical property and shear force values (Table 6). The high level of minced garlic caused a significantly $(P \leq 0.15)$ lower ideal ratio score of color, indicating 
a less color intensity in Mum. However, the high level led to more odor intensity in Mum, significantly $(P \leq 0.20)$. Addition of more garlic resulting in stronger odor was also found previously in Mum (Metha and Sereepaowong, 1998). Garlic is used as a flavoring component in several fermented sausages (GonzálezFernández et al., 2003; Phromraksa et al., 2003; Soyer et al., 2005; Visessanguan et al., 2005). Allicin in garlic juice and the vapor are responsible for its flavor (Davidson and Taylor, 2007).

Only two attributes, color and homogeneity, were influenced significantly by level of roasted rice powder (Table 7). Mum samples obtained significantly $(P \leq 0.05)$ higher in ideal ratio score of color when it was manufactured with high level of roasted rice powder. On the other hand, the high level of roasted rice powder rendered a significant $(P \leq 0.15)$ decrease in ideal ratio score of homogeneity.

Salt was added to act as a curing agent in Mum production. Using high level of salt led to a significant $(P \leq 0.20)$ increase in $\mathrm{pH}$ which corresponding to a significant $(P \leq 0.15)$ decrease in total acidity (Table 6). A similar report was made, however, in the beef Mum where 2.5\% salt resulted in higher $\mathrm{pH}$ and lower total acidity than that manufactured with $2.0 \%$ salt (Metha and Sereepaowong, 1998). It has been known that lactic acid bacteria are the major producers of lactic acid which is responsible for the decrease in $\mathrm{pH}$ and the increase in total acidity of the fermented meat product. Using higher salt level decreased lactic acid bacteria counts and increased $\mathrm{pH}$ of fermented sausages (Laranjo et al., 2015; Laranjo et al., 2016). It has been reported that low acidification rates were accompanied by slow lactic acid bacteria growth rates in fermented sausages (Aro et al., 2010). Microbial growth is inhibited by salt because sodium ions and chloride ions immobilize water molecules in food and microorganisms, resulting in lack of available water molecules for microorganisms' growth (Honikel, 2010).

Moreover, salt had a significant $(P \leq 0.05)$ effect on saltiness of Mum. Ideal ratio score of saltiness was higher when salt content increased (Table 7). This indicates that Mum produced with high level of salt was saltier. It is important to note that ideal ratio scores of color and sourness were significantly $(P \leq 0.10)$ higher when high level of salt was employed (Table 7). The effects of salt level on ideal ratio score of saltiness, color and sourness observed in this study were similar to those reported by Phromraksa et al. (2003).

The level of ground glutinous rice had a significant effect on only one dependent variable, odor (Table 7). Using high level of ground glutinous rice increased significantly $(P \leq 0.10)$ ideal ratio score of odor to the ideal ratio (1.0). According to Table 6, increasing of glutinous rice level gave rise to elevation of total acidity of Mum. This was in agreement with Cheijarern (1988). It has been known that glutinous rice serves as carbon and energy sources for the lactic acid bacteria to grow and produce lactic acid in fermented Mum. The satisfactory odor of Mum when high level of glutinous rice was used might be due to higher formation of lactic acid which can enhance the growth of important 
microorganisms involved with production of chemical compounds responsible for its odor and, at the same time, inhibited the spoilage microorganisms.

High level of sodium nitrite caused a significant $(P \leq 0.15)$ reduction in total acidity of Mum (Table 6 ). The growth of lactic acid bacteria in dry fermented sausage was retarded, if the concentration of added nitrite was too high, however, reduction in added nitrite to the suitable concentration promoted the growth of lactic acid bacteria (Zeuthen, 1995; Kurt and Zorba, 2010). To the best of our knowledge, there is limit information relating the effect of sodium nitrite on total acidity of fermented sausage; previous researches only focused on other characteristics such as lactic acid bacteria counts and $\mathrm{pH}$ values. Within the first 4 days of Chorizo fermentation, lactic acid bacteria counts were not affected by the level of sodium nitrite (González and Díez, 2002). On the other hand, at day 6 and 8 of fermentation the lactic acid bacteria counts of sausages containing 50 ppm of sodium nitrite were higher than those of sausage with higher level of sodium nitrite (150 ppm) (González and Díez, 2002). In addition, there was an inverse relationship between sodium nitrite concentration and the counts of Lactococcus lactis, starter culture, in Salami (Scannell et al., 2001). Therefore, the high level of sodium nitrite in the present study might retard the growth of some lactic acid bacteria strains in Mum, resulting in less acid production as described above.

As expected, a positive relation between sodium nitrite level and ideal ratio score in color was observed with significance level of $P \leq 0.20$ as presented in Table 7. Phromraksa et al. (2003) observed a similar situation in Sai Krok Prew, a Thai fermented sausage. Nitrites in fermented sausage react with the heme moiety of myoglobin to facilitate the development of cured color (Zeuthen, 1995).

On the other hand, high level of sodium nitrite significantly $(P \leq 0.20)$ decreased ideal ratio score of odor (Table 7), inferring the lowered intensity of odor in the sausage. The aroma of fermented sausages is a combination of several elements. Lactic acid, being the main acid produced during fermentation, contributes the tangy odor of fermented sausage (Cocconcelli and Fontana, 2010). Less concentration of total acidity as lactic acid when using high level of sodium nitrite (Table 6) might be a reason of the reduction of Mum odor. Moreover, the volatile compounds produced through proteolytic and lipolytic activities of staphylococci play an important role in aroma formation of fermented meat (Cocconcelli and Fontana, 2010). High level of sodium nitrite might not be the optimum level to the development of volatiles compounds leading to a lowered intensity of odor in the sausage. Finally, lipid oxidation derived compounds have been considered essential to the proper formation of flavor of cured meat products (Shahidi et al., 1986). Nitrite acts as antioxidant by sequestering oxygen in meat (Honikel, 2010) and its antioxidant effect in dry fermented sausage has been proven (Hospital et al., 2012). It is not surprising that lowered sensory ideal ratio score of odor in Mum produced with high sodium nitrite level. Nitrite may exert 
antioxidant activity resulting in low development of desirable volatile compounds from lipid oxidation.

$P$. acidilactici KK3 affected significantly on ideal ratio score of color $(P \leq 0.10)$, homogeneity $(P \leq 0.20)$ and odor $(P \leq 0.20)$ of Mum (Table 7$)$. Ideal ratio score of these attributes increased when using low level of $P$. acidilactici KK3. The effect of $P$. acidilactici KK3 on odor of Mum in this study was opposite to the effect of $P$. acidilactici MA $18 / 5 \mathrm{M}$ in beef sausage because addition of $P$. acidilactici MA $18 / 5 \mathrm{M}$ had a positive effect on odor of the product (Slima et al., 2018).

As expected, adding $P$. acidilactici KK3 at high level resulted in significantly $(P \leq 0.15)$ higher total acidity than the low level usage (Table 6). It has been known that Pediococcus produces lactic acid and thus is used as starter culture for acidification fermented sausage (Jessen, 1995). Som Fug, a Thai fermented fish, inoculated with $P$. acidilactici as starter exhibited significantly higher total acidity than Som Fug without added starter culture (Riebroy et al., 2008).

Similarly, Mum produced with high level of L. plantarum subsp. plantarum $\mathrm{CP} 1$ had significantly higher total acidity than Mum produced without the addition of this starter culture (Table 6). L. plantarum is used as starter culture for meat fermentation and ferments available carbohydrates to organic acid, primarily lactic acid (Cocconcelli and Fontana, 2010). Som Fug inoculated with L. plantarum as starter exhibited significantly higher total acidity than Som Fug without added this starter culture (Riebroy et al., 2008).

Likewise, the samples added with high level of $L$. plantarum subsp. plantarum $\mathrm{CP} 1$ led to a significantly $(P \leq 0.15)$ higher shear force compared to Mum manufactured without addition of this starter culture (Table 6). High shear force indicates the high consistency or cohesion of Mum. Lactic acid production causing $\mathrm{pH}$ of fermented meat approaches isoelectric point where protein coagulation and water holding capacity reduction take place, resulting in a consistency fermented meat (Toldrá et al., 2001). Thus, the greater lactic acid production in Mum processed with high level of L. plantarum subsp. plantarum CP1 possibly increased shear force of Mum.

Table 7 shows that low level of L. plantarum subsp. plantarum KK6 significantly $(P \leq 0.15)$ increased color ratio score of Mum. However, there were no significant differences in the instrument color parameters between Nham fermented with the addition of L. plantarum BCC 9546 as starter culture and Nham naturally fermented (no added starter culture) (Luxananil et al., 2009). Mum produced with high level of L. plantarum subsp. plantarum KK6 had significantly $(P \leq 0.20)$ higher ideal ratio score of sourness, indicating a greater sourness, than Mum produced without the addition of this starter culture (Table 7). The greater sourness in Mum might result from the higher production of total acidity when addition of this starter culture in Mum (Table 6). 
To determine the major factors (ingredients and starter cultures) that affect quality of Mum by using the Plackett-Burman design, the number of quality influenced significantly by each factor was considered from Tables 6 and 7. It was found that salt significantly influenced the higher number of quality i.e. color, sourness, saltiness, $\mathrm{pH}$ and total acidity. Sodium nitrite and $P$. acidilactici KK3 showed significant effects on color, homogeneity, odor and total acidity. The other factors such as ground garlic, roasted rice powder, ground glutinous rice, $L$. plantarum subsp. plantarum $\mathrm{CP} 1$ and L. plantarum subsp. plantarum KK6 showed statistically significant effect on two or less quality. Therefore, it can be concluded that salt, sodium nitrite and $P$. acidilactici KK3 were the main variables affecting quality of Mum, while ground garlic, roasted rice powder, ground glutinous rice, L. plantarum subsp. plantarum $\mathrm{CP} 1$ and L. plantarum subsp. plantarum KK6 were the minor influencing variables. On the other hand, W. cibaria $\mathrm{CM} 7$ was an insignificant factor influencing Mum quality.

Plackett-Burman design is the primary tool to identify the effects of various inputs but cannot be used to optimize the level of each variable. Therefore, further steps for Mum production should emphasize on optimal investigation of salt, sodium nitrite and $P$. acidilactici $\mathrm{KK} 3$ in order to obtain the most acceptable Mum recipe.

\section{CONCLUSION}

The present study involved the use of Plackett-Burman design to screen the significant factors affecting sensory quality, $\mathrm{pH}$, total acidity and shear force of Mum. It was found that 8 factors from 9 showed significant effects on properties of Mum. However, only salt, sodium nitrite and P. acidilactici KK3 were the most important variables affecting properties of Mum. Salt exhibited negative effect on total acidity and positive effect on ideal ratio of saltiness, color and sourness and $\mathrm{pH}$ of Mum. High level of sodium nitrite caused a reduction in total acidity and ideal ratio score of odor but it increased ideal ratio of color and homogeneity. Finally, addition of $P$. acidilactici KK3 in Mum production resulted in higher formation of total acidity but reduced ideal ratio score of color, homogeneity and odor.

\section{ACKNOWLEDGEMENTS}

The authors thank of National Center for Genetic Engineering and Biotechnology, Thailand, for financial support of this work. 


\section{REFERENCES}

Anderson, A.M. 1981. Process improvement for small food companies in developing countries. New Zealand: Massey University.

AOAC. 2000. Official methods of analysis of AOAC international. $17^{\text {th }}$ ed. USA: Association of Analytical Communities.

Aro, J.M.A., Nyam-Osor, P., Tsuji, K., Shimada, K., Fukushima, M., and Sekikawa, M. 2010. The effect of starter cultures on proteolytics changes and amino acid content in fermented sausages. Food Chemistry. 119: 279285. https://doi.org/10.1016/j.foodchem.2009.06.025

Barbut, S., Wood, J., and Marangoni, A. 2016. Quality effects of using organogels in breakfast sausage. Meat Science. 122: 84-89. https://doi.org/10.1016/ j.meatsci.2016.07.022

Cheijarern, S. 1988. Study on the optimum contents of salt and waxy rice on the alteration of $\mathrm{pH}$, lactic acid and reducing sugar in Mum. [special problem]. Bangkok: King Mongkut's Institute of Technology Ladkrabang.

Cocconcelli, P.S., and Fontana, C. 2010. Starter cultures for meat fermentation. In: Toldrá, F., editor. Handbook of meat processing. Iowa: Blackwell Publishing. p.199-218.

Coffey, A., Ryan, M., Ross, R.P., Hill, C., Arendt, E., and Schwarz, G. 1998. Use of a broad-host-range bacteriocin-producing Lactococcus lactis transconjugant as an alternative starter for salami manufacture. International Journal of Food Microbiology. 43(3): 231-235. https://doi.org/10.1016/ S0168-1605(98)00115-9

Cooper, H.R., Earle, M.D., and Triggs, C.M. 1989. Ratios of ideals-a new twist to an old idea. In: Wu, L.S., editor. Product testing with consumers for research guidance. Philadelphia: American Society for Testing and Materials. p.5463.

Davidson, P.M., and Taylor, T.M. 2007. Chemical preservatives and antimicrobial compounds. In: Doyle, M.P., and Beuchat, L.R., editors. Food microbiology: fundamentals and frontiers. Washington, D.C.: ASM Press. p.713-745.

González, B., and Díez, V. 2002. The effect of nitrite and starter culture on microbiological quality of 'Chorizo'- a Spanish dry cured sausage. Meat Science. 60: 295-298. https://doi.org/10.1016/S0309-1740(01)00137-1

González-Fernández, C., Santos, E.M., Jaime, I., and Jordi, R. 2003. Influence of starter cultures and sugar concentrations on biogenic amine contents in Chorizo dry sausage. Food Microbiology. 20(3): 275-284. https://doi.org/ 10.1016/S0740-0020(02)00157-0

Honikel, K.O. 2010. Curing. In: Toldrá, F., editor. Handbook of meat processing. Iowa: Blackwell Publishing. p.125-141. 
Hospital, X.F., Hierro, E., and Fernández, M. 2012. Survival of Listeria innocua in dry fermented sausages and changes in the typical microbiota and volatile profile as affected by the concentration of nitrate and nitrite. International Journal of Food Microbiology. 153(3): 395-401. https://doi.org/10.1016/ j.ijfoodmicro.2011.11.032

Hu, R. 1999. Food product design: a computer-aided statistical design. USA: CRC Press.

Jaichumjai, P., Valyasevi, R., Assavanig, A., and Kurdi, P. 2010. Isolation and characterization of acid-sensitive Lactobacillus plantarum with application as starter culture for Nham production. Food Microbiology. 27(6): 741-748. https://doi.org/10.1016/j.fm.2010.03.014

Jessen, B. 1995. Starter cultures for meat fermentations. In: Campbell-Platt, G., and Cook, P.E., editors. Fermented meats. U.K.: Chapman \& Hall. p.130159.

Joglekar, A.M., and May, A.T. 1991. Product excellence through experimental design. In: Graf, E., and Saguy, I.S., editors. Food product development: from concept to the marketplace. New York: An AVI book. p.211-230.

Kurt, S., and Zorba, O. 2010. Biogenic amine formation in Turkish dry fermented sausage (Sucuk) as affected by nisin and nitrite. Journal of the Science of Food and Agriculture. 90(15): 2669-2674. https://doi.org/10.1002/jsfa. 4138

Laranjo, M., Agulheiro-Santos, A.C., Potes, M.E., Cabrita, M.J., Garcia, R., Fraqueza, M.J., and Elias, M. 2015. Effects of genotype, salt content and calibre on quality of traditional dry-fermented sausages. Food Control. 56: 119-127. https://doi.org/10.1016/j.foodcont.2015.03.018

Laranjo, M., Gomes, A., Agulheiro-Santos, A.C., Potes, M.E., Cabrita, M.J., Garcia, R., Rocha, J.M., Roseiro, L.C., Fernandes, M.J., Fernandes, M.H., et al. 2016. Characterisation of 'Catalão' and 'Salsichão' Portuguese traditional sausages with salt reduction. Meat Science. 116: 34-42. https://doi.org/10.1016/j.meatsci.2016.01.015

Li, Y., Liu, Z., Cui, F., Xu, Y., Zhao, H., and Liu, Z. 2007. Application of statistical experimental design to optimize culture requirements of Aspergillus sp. Zh26 producing xylanase for degradation of arabinoxylans in mashing. Journal of Food Science. 72(5): E320-E329. https://doi.org/10.1111/j.17503841.2007.00389.x

Lu, R., and Abbott, J.A. 2004. Force-deformation techniques for measuring texture. In: Kilcast, D., editor. Texture in food. England: Woodhead Publishing Limited. p.109-145.

Luxananil, P., Promchai, R., Wanasen, S., Kamdee, S., Thepkasilkul, P., Plengvidhya, V., Visessanguan, W., and Valyasevi, R. 2009. Monitoring Lactobacillus. plantarum BCC 9546 starter culture during fermentation of Nham, a traditional Thai pork sausage. International Journal of Food Microbiology. 129: 312-315. https://doi.org/10.1016/j.ijfoodmicro.2008. 12.011 
Maipueang, P. 1988. Study on types and numbers of microorganism in Thai beef sausage (Mum) fermentation. [special problem]. Bangkok: King Mongkut's Institute of Technology Ladkrabang.

Metha, C., and Sereepaowong, V. 1998. Study of the effect of salt, garlic and prague powder on Mum product. [special problem]. Chiang Mai: Maejo University.

Modi, V.K., and Maya, P. 2008. Quick and reliable screening of compatible ingredients for the formulation of extended meat cubes using PlackettBurman design. LWT - Food Science and Technology. 41(5): 878-882. https://doi.org/10.1016/j.lwt.2007.06.002

Phromraksa, P., Wiriyacharee, P., Rujanakraikarn, L., and Pathomrungsiyungkul, P. 2003. Identification of main factors affecting quality of Thai fermented pork sausage (Sai Krok Prew). Chiang Mai University Journal of Natural Sciences. 2(2): 89-96.

Riebroy, S., Benjakul, S., and Visessanguan, W. 2008. Properties and acceptability of Som-fug, a Thai fermented fish mince, inoculated with lactic acid bacteria starters. LWT - Food Science and Technology. 41(4): 569-580. https://doi.org/10.1016/j. 1wt.2007.04.014

Scannell, A.G.M., Hill, C., Ross, R.P., Schwarz, G., and Arendt, E.K. 2001. Effect of nitrite on a bacteriocinogenic Lactococcus lactis transconjugant in fermented sausage. European Food Research and Technology. 213: 48-52. https://doi.org/10.1007/s002170100306

Shahidi, F., Rubin, L.J., and Dsouza, L.A. 1986. Meat flavor volatiles - a review of the composition, techniques of analysis, and sensory evaluation. Food Science and Nutrition. 24: 141-243.

Slima, S.B., Ktari, N., Triki, M., Trabelsi, I., Abdeslam, A., Moussa, H., Makni, I., Herrero, A.M., Colmenero, F.J., Capillas, C.R., et al. 2018. Effects of probiotic strains, Lactobacillus plantarum TN8 and Pediococcus acidilactici, on microbiological and physico-chemical characteristics of beef sausages. LWT-Food Science and Technology. 92: 195-203. https:// doi.org/10.1016/j.1wt.2018.02.038

Soyer, A., Ertaş, A.H., and Üzümcüoğlu, Ü. 2005. Effect of processing conditions on the quality of naturally fermented Turkish sausages (Sucuks). Meat Science. 69(1): 135-141. https://doi.org/10.1016/j.meatsci.2004.06.015

Toldrá, P., Sanz, Y., and Flores, M. 2001. Meat fermentation technology. In: Hui, Y.H., Nip, W., Rogers, R.W., and Young, O.A., editors. Meat science and applications. New York: Marcel Dekker Inc. p.537-561.

Vichitphan, S., Harmsupothi, K., and Vichitphan, K. 2008. Isolation of effective microbial strains for the production of Mum and Sai Krok-Esan. Khon Kaen: Khon Kan University. 
Visessanguan W, Benjakul, S., Panya, A., Kittikun, C., and Assavanig, A. 2005. Influence of minced pork and rind ratios on physico-chemical and sensory quality of Nham - a Thai fermented pork sausage. Meat Science. 69: 355362. https://doi.org/10.1016/ j.meatsci.2004.08.006

Wiriyacharee, P. 2012. Advanced experimental design. Chiang Mai: Chiang Mai University.

Yang, H., Han, M., Bai, Y., Han, Y., Xu, X., and Guanghong, Z. 2015. High pressure processing alters water distribution enabling the production of reduced-fat and reduced-salt pork sausages. Meat Science. 102: 69-78. https://doi.org/10.1016/ j.meatsci.2014.10.010

Yordrak, K. 2003. Effect of sodium nitrite, sodium ascorbate and smoking on quality and shelf life of Mum (traditional Thai fermented beef sausage) [master thesis]. Bangkok: Kasetsart University.

Zeuthen, P. 1995. Historical aspects of meat fermentations. In: Campbell-Platt, G., and Cook, P.E., editors. Fermented meats. London: Blackie Academic and Professional. p.53-68. 